\title{
Influence of Water Flow Velocity on the Hazardous Chemical Containment Boom
}

\author{
Panpan Zhang 1, 2, a , Weiting Ning 1, 2, b, Dewen Zhang 1, 2, c and Yunfei Zou 2,d \\ ${ }^{1}$ Shuikeyunda Transportation Technology Development Co. Ltd, Beijing 100088, China. \\ ${ }^{2}$ China Waterborne Transport Research Institute, Beijing 100088, China. \\ azhangpanpan@wti.ac.cn, ํningwt@wti.ac.cn, zhangdw@wti.ac.cn, dzouyunfei@wti.ac.cn
}

Keywords: hazardous chemical, benzene, containment boom, flow velocity, blocking performance.

\begin{abstract}
Along with the accelerating process of economy, hazardous chemical productions and consumptions increase rapidly, the transport throughout of hazardous chemicals in the Yangtze River has been increasing. Once the hazardous chemical leakage happens, it will cause serious damage to water and marine life in Yangtze River. The containment boom is usually used for chemical blocking or diverting. In this paper, the performance of the containment boom for hazardous chemical blocking was investigated via a software package Flow-3D. According to the simulations, the water flow velocity greatly affects the performance of the containment boom.
\end{abstract}

\section{Introduction}

Chemical is a very important kind of raw materials for industry. With the rapid process of the western development strategy and domestic economy, transportation of hazardous chemical along the Yangtze River is becoming more often than before. And this will bring leakage risk of the hazardous chemical. It is urgent to deal with the chemical leakage. In recent years, studies [1-4] were carried out to evaluate the behavior of different chemicals after the spill and the emergency response measures for different type of chemicals.

During the handling of chemical spill accident, the containment boom is usually used for the chemical blocking or diverting. Hydrological conditions such as flow velocity and tide height affect the performance of the containment boom. Thus, it is quite necessary to find out the influences of hydrological conditions on the containment boom.

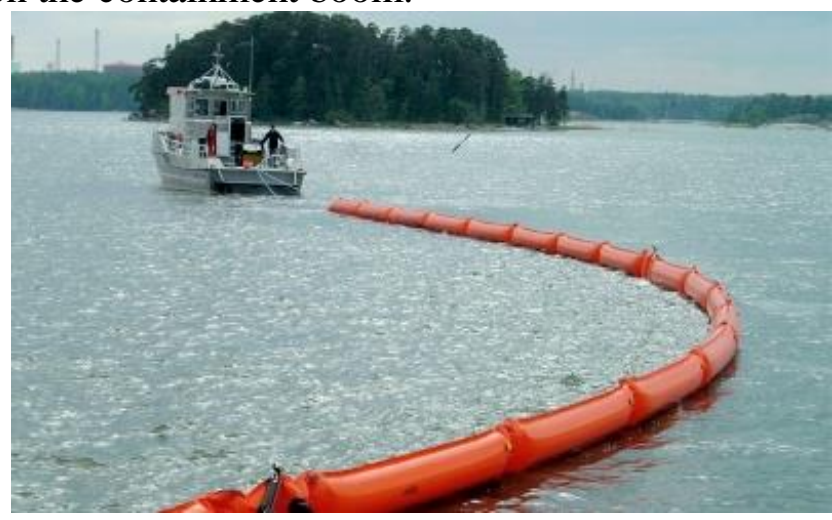

Figure 1 the containment boom

In this paper, the structure of the containment boom was introduced. The software package Flow-3D was selected for simulation. The water flow velocity was chosen to evaluate its influence on the performance of the containment boom. The results show that the water flow velocity greatly affects the chemical blocking performance of the containment boom.

\section{Structure of the containment boom}

There are several types of the containment booms according to the floatation structure such as the solid floatation boom, the fence boom, the external tension boom and so on. The containment boom 
shown in Figure 2 is basically consisted of the anchor point, the ballast, the bridle, the floatation chamber, the end connector, the floatation, the shirt and so on.

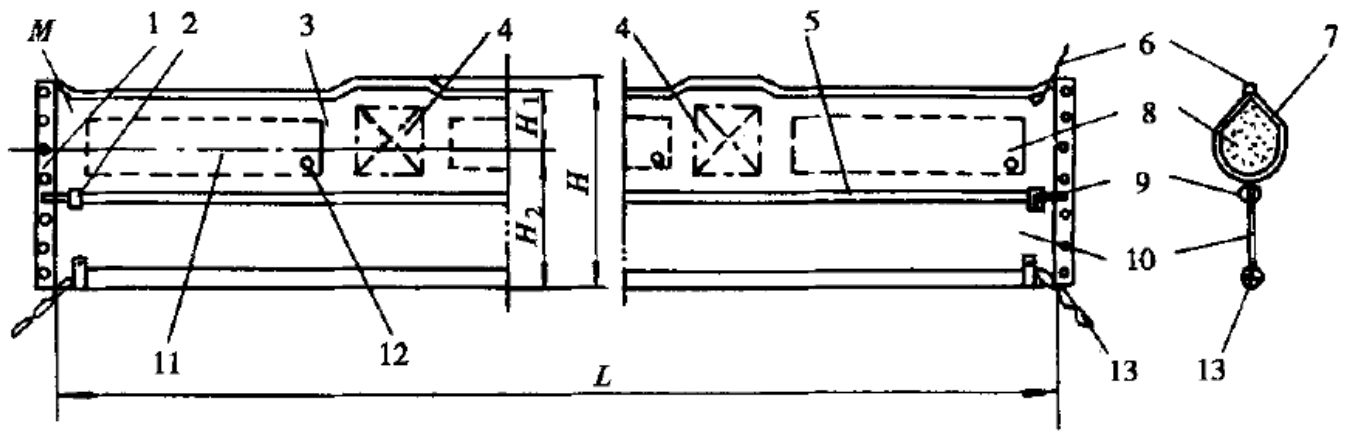

1-the end connector, 2-the platen, 3,7-the membrane, 4-the flexibility gap section, 5-external tension belt, 6-spinal cord, 8-floatation, 9-the anchor base, 10-the shirt, 11-draft line, 12-the outlet, 13-the

ballast, L-the boom section length, M- the boom body, H-the overall height, H1-the freeboard, H2-draft

Figure 2 the structure of the containment boom

The containment boom is used for the chemical blocking or diverting to certain areas for further treatment. In order to analyze the performance the boom, simplifying approach was conducted for the boom shown in Figure 3.

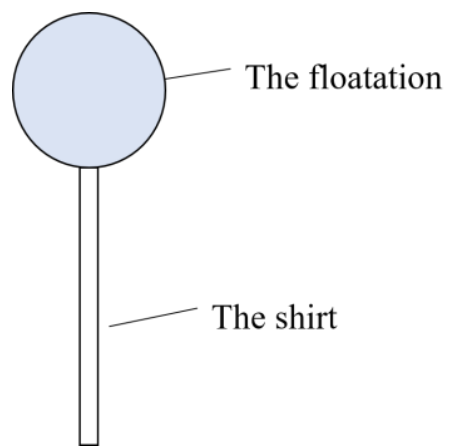

Figure 3 the structural diagram of the containment boom

\section{Simulation settings}

The height of the boom shirt is 1 meter, and the thickness of the shirt is 1 centimeter. The diameter of the floatation is 0.55 meter. During simulations, the size of the mesh near the boom is $0.01 \mathrm{~m}$ in length and $0.01 \mathrm{~m}$ in depth. The size of mesh for other calculation area is $0.02 \mathrm{~m}$ in length and $0.02 \mathrm{~m}$ in depth show in figure 4.

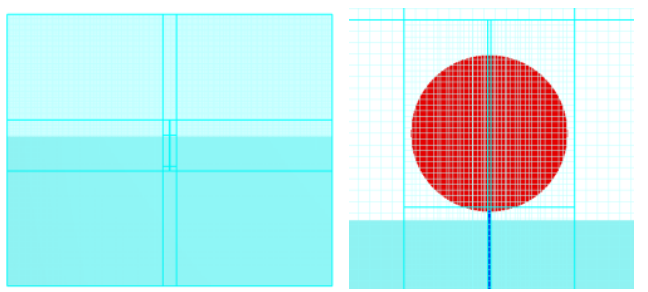

Figure 4 the mesh setting for the calculation area

In simulations, the calculation area of this study is 14 meter in length and 6.7 meter in depth. The boom was placed 7 meter away from the calculation area inlet shown in Figure 5. In the calculation area, 0.2 ton of benzene was placed. Different water flow velocity such as $0.25 \mathrm{~m} / \mathrm{s}, 0.5 \mathrm{~m} / \mathrm{s}, 1 \mathrm{~m} / \mathrm{s}$ and $1.5 \mathrm{~m} / \mathrm{s}$ was set for simulations. 


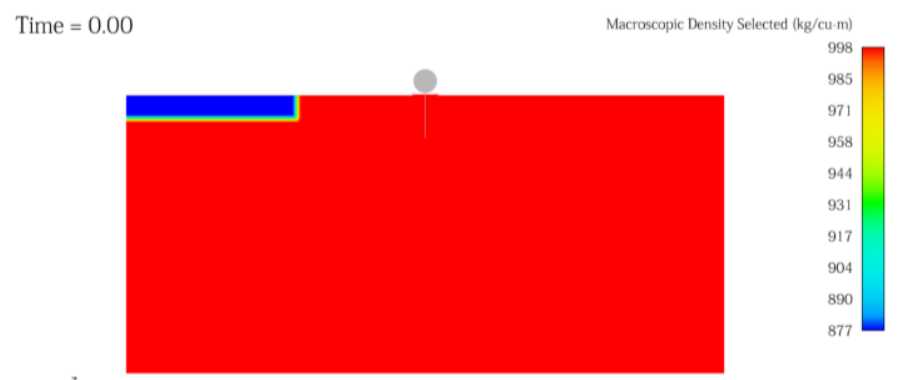

Figure 5 the setting of the simulation

\section{Results and Discussion}

In order to evaluate the performance of the boom for chemical blocking, the blocking efficiency was introduced. The blocking results at the same simulation time of different water flow velocity were used for comparison. Figure 6 and Figure 7 are the results for different water flow velocities at the simulation time of 10 second and 30 second. It can be concluded that the flow velocity greatly affects the blocking performance of the containment boom. When the velocity increases, more chemical of benzene will escape from the bottom of the shirt.

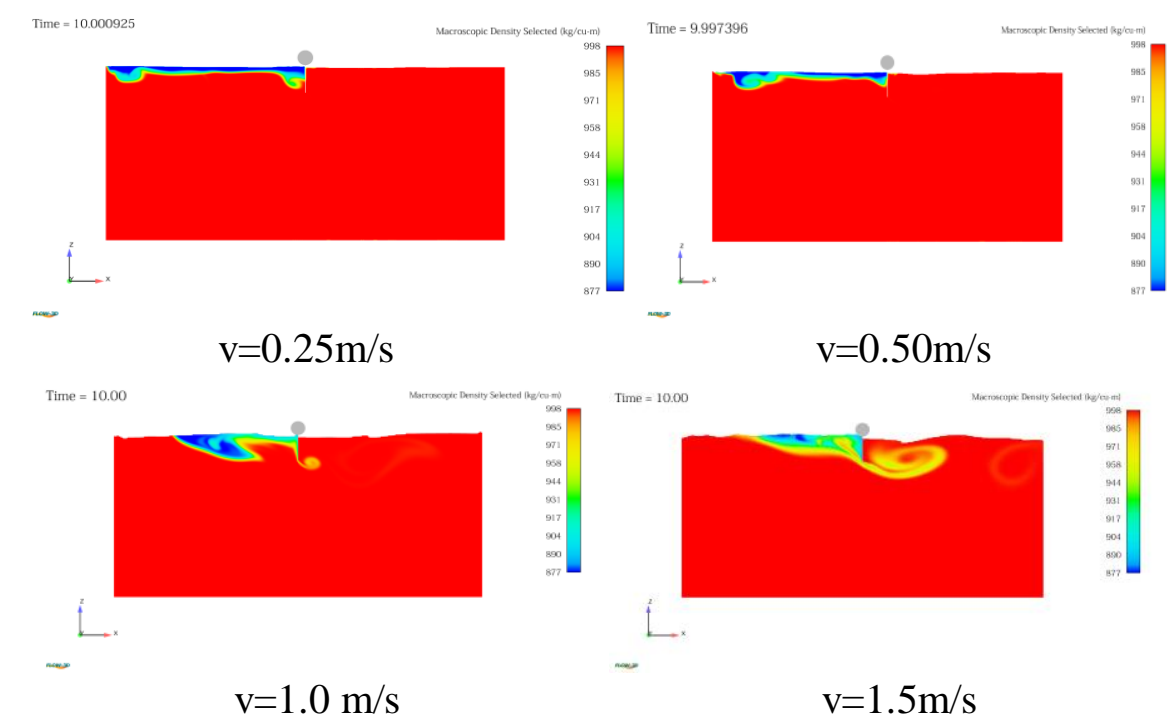

Figure 6 blocking performance of the boom at different velocities at time of 10 second

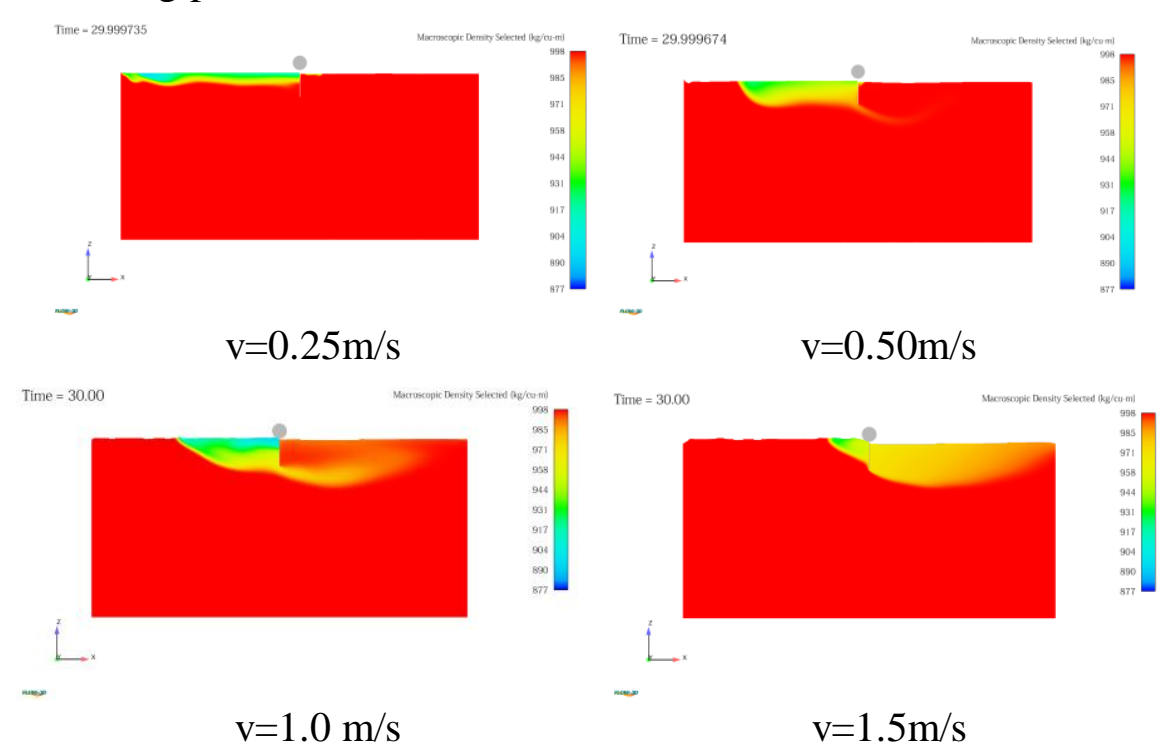

Figure 7 blocking performance of the boom at different velocities at time of 30 second 
Figure 8 reveals the blocking performance of the boom at different time at the velocity of $0.25 \mathrm{~m} / \mathrm{s}$. It can be seen that as time passes, the benzene layer spread out and got close to the boom. At the time of 185 second, there was only 7.6 percentage of the overall benzene escaping from the bottom of the shirt due to the small water flow velocity.

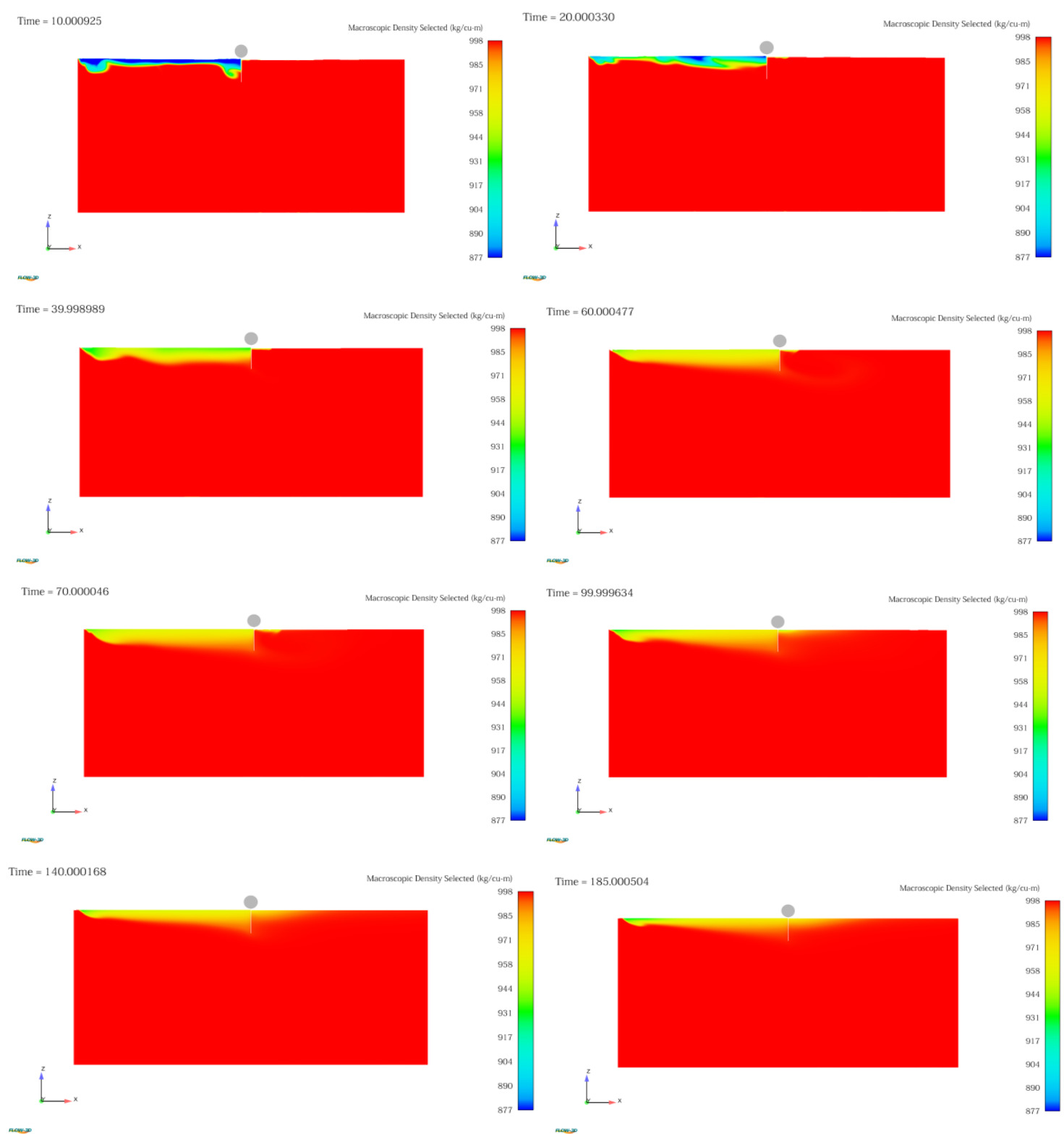

Figure 8 blocking performance of the boom at different time at the velocity of $0.25 \mathrm{~m} / \mathrm{s}$

Table 1 shows the percentage of chemical escaping from the bottom of the boom. It can be concluded in two aspects. On one hand, more benzene escaped from the bottom of the boom with simulation time going on at the same water flow velocity. On the other hand, more benzene escaped when the water flowed faster at the same simulation time. When the water flow velocity exceeded $0.5 \mathrm{~m} / \mathrm{s}$, the effect of the containment boom for benzene blocking got worse.

Table 1 the results for the different simulation conditions

\begin{tabular}{|c|c|c|c|c|c|c|c|c|}
\hline Velocity $(\mathrm{m} / \mathrm{s})$ & Time(s) & 20 & 40 & 60 & 80 & 100 & 140 & 185 \\
\hline 0.25 & & 0 & 0 & 1.3 & 2.8 & 4.7 & 7.0 & 7.6 \\
\hline 0.5 & & 0 & 4.6 & 10.2 & 13.8 & 14.6 & 15.0 & 17.7 \\
\hline 1.0 & & 4.0 & 45.9 & 75.3 & 88.3 & 93.2 & 94.6 & 95.4 \\
\hline 1.5 & & 68.5 & 87.3 & 94.2 & 94.2 & 94.3 & 94.3 & 94.6 \\
\hline
\end{tabular}




\section{Conclusion}

Hazardous chemical leakage in the Yangtze River has become a serious problem. It will bring water pollution and further cause ecological crisis. In this paper, the performance of the containment boom for hazardous chemical blocking was investigated via a software package Flow-3D. According to the simulations, the water flow velocity greatly affects the performance of the containment boom. When the water flow velocity exceeded $0.5 \mathrm{~m} / \mathrm{s}$, the benzene blocking of the containment boom got worse. When the velocity exceeded $1.0 \mathrm{~m} / \mathrm{s}$, the containment boom no longer worked. Attention have to be paid when the boom is chosen to deal with the chemical leakage in water.

\section{References}

[1]. Wang Zhixia, Emergency Response of Dangerous Chemical Spill Accident-Take Styrene as Example, environmental science and management, 2011, 36(9): 8-11.

[2]. Cedre. Chemical response guide [M], 2008: 345-400.

[3]. Ric Jensen. Inland Chemical Spills. Texas Water Resources Institute [J], 2001, 11(2): 126-137.

[4]. Zhang Jianghua, Zhao Laijun. Risk analysis of dangerous chemicals transportation, System Engineering Theory \& Practice, 2007, 27(12): 117-122. 